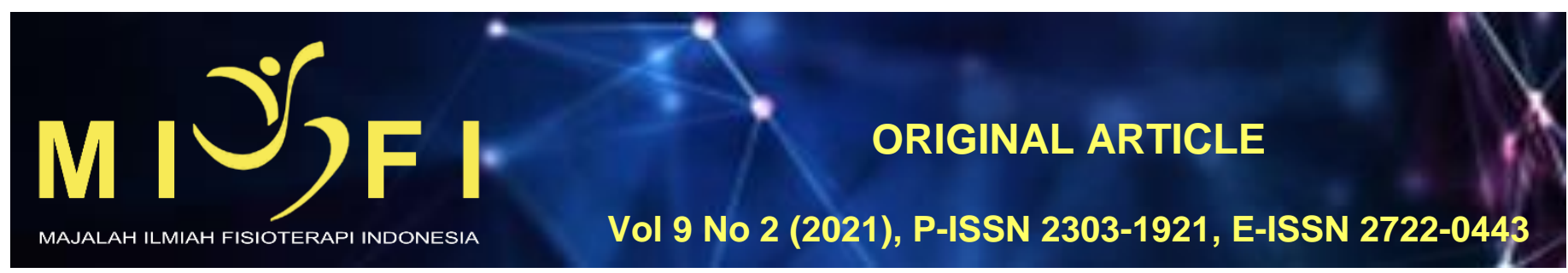

\title{
HUBUNGAN KOORDINASI MATA TANGAN DAN KEKUATAN OTOT GENGGAM DENGAN KETEPATAN PUKULAN FOREHAND SMASH PADA ATLET BULUTANGKIS
}

\author{
Ni Made Anggi Kristiyanti ${ }^{1}$, Made Hendra Satria Nugraha ${ }^{2}$, Indira Vidiari Juhanna ${ }^{3}$, I Nyoman Adiputra ${ }^{4}$ \\ ${ }^{1}$ Program Studi Sarjana Fisioterapi dan Profesi Fisioterapi Fakultas Kedokteran Universitas Udayana \\ ${ }^{2}$ Departemen Fisioterapi, Fakultas Kedokteran Universitas Udayana \\ ${ }^{3,4}$ Departemen IImu Faal, Fakultas Kedokteran Universitas Udayana \\ anggikristy18@gmail.com
}

\begin{abstract}
ABSTRAK
Pukulan smash banyak didominasi oleh kekuatan otot lengan, namun kekuatan genggaman tangan juga memiliki pengaruh yang besar dalam pukulan smash ini dikarenakan kekuatan genggaman tangan sangat berperan pada penempatan shuttle cock. Permainan bulutangkis juga memaksa pemain untuk dapat bereaksi secara tepat dan cepat. Koordinasi mata dan tangan sangat perlu diperhatikan agar dapat bereaksi secara tepat dan cepat dalam permainan bulutangkis ini. Tujuan penelitian ini adalah untuk mengetahui hubungan koordinasi mata tangan dan kekuatan otot genggam dengan ketepatan pukulan forehand smash. Penelitian ini adalah penelitian observasional yang menggunakan rancangan penelitian desain cross sectional (potong lintang), di mana tiap subjek hanya diobservasi satu kali dan pengukuran variable subjek dilakukan pada saat pemeriksaan. Pengambilan sampel dilakukan dengan teknik proportionate cluster random sampling. Dari analisis data menggunakan uji korelasi non parametrik spearman rho didapatkan hubungan antara koordinasi mata tangan dengan ketepatan pukulan forehand smash dimana diperoleh nilai $p$ sebesar $(p=0,000)$ dan nilai korelasi sebesar $(r=0,456)$ (korelasi sedang), dan didapatkan hubungan antara kekuatan otot genggam dengan ketepatan pukulan forehand smash dimana diperoleh nilai $p$ sebesar $(p=0,000)$ dan nilai korelasi sebesar $(r=0,503)$ (korelasi sedang). Dan dilakukan analisis multivariate regresi ganda untuk mengetahui hubungan koordinasi mata tangan dan kekuatan otot genggam dengan ketepatan pukulan forehand smash dan didapatkan nilai $\mathrm{p}$ sebesar $(p=0,000)$
\end{abstract}

Kata Kunci: koordinasi mata tangan, kekuatan otot genggam, ketepatan pukulan forehand smash

\section{THE CORRELATION OF HAND EYE COORDINATION AND HAND GRIP STRENGTH WITH THE ACCURACY OF FOREHAND SMASH IN BADMINTON ATHLETES}

\section{ABSTRACT}

Smash is mostly dominated by the arm muscle strength, but the strength of the hand grip also has a great influence on this smash because the strength of the hand grip is very important in the placement of the shuttle cock. Badminton games also force players to be able to react appropriately and quickly. Eye and hand coordination really need to be considered in order to react appropriately and quickly in this badminton game. This study aimed to determine the relationship between hand eye coordination and handgrip strength with the accuracy of the forehand smash. This study was an observational study using a cross sectional study design, in which each subject was only observed once and the measurement of subject variables were carried out at the time of examination. Sampling was done by proportionate cluster random sampling technique. Spearman rho non parametric correlation test obtained a relationship between hand eye coordination with the accuracy of the forehand smash where $p=0.000$ and correlation values of $r=0.456$ (moderate correlation), and obtained relationships between handgrip strength with the accuracy of the forehand smash where $\mathrm{p}=0.000$ and correlation values of $\mathrm{r}=0.503$ (moderate correlation) were obtained. And multivariate multiple regression analysis was performed to determine the relationship between hand eye coordination and handgrip strength with the accuracy of the forehand smash and the results obtained $p=0.000$.

Keywords: hand eye coordination, handgrip strength, accuracy of the forehand smash

\section{PENDAHULUAN}

Olahraga adalah aktivitas fisik yang dapat memperlambat terjadinya penurunan fungsi kognitif. ${ }^{1}$ Bulutangkis merupakan olahraga yang populer karena dapat dilakukan oleh siapapun tanpa memandang usia atau pengalaman. Permainan bulutangkis melibatkan sebagian besar tubuh, di mana permainan bulutangkis dapat meningkatkan kebugaran fisik terutama koordinasi gerakan, kecepatan, kekuatan, dan stamina. Pemain bulutangkis yang sudah berpengalaman memiliki kemampuan analisis cepat dari situasi pertandingan dan antisipasi gerakan lawan dalam membuat keputusan instan mengenai jenis gerakan lawan, posisi, dan kekuatan yang diterapkan. ${ }^{2}$

Smash dalam permainan bulutangkis merupakan pukulan penting yang digunakan sebagai titik awal serangan. Pukulan smash ini bisa berubah menjadi pukulan yang menentukan kemenangan permainan. ${ }^{3}$ Pukulan smash banyak didominasi oleh kekuatan otot lengan, namun kekuatan genggaman tangan juga memiliki pengaruh yang besar dalam pukulan smash ini dikarenakan kekuatan genggaman tangan sangat berperan pada penempatan shuttle cock. ${ }^{4}$ Permainan bulutangkis juga memaksa pemain untuk dapat bereaksi secara tepat dan cepat. Koordinasi mata dan 
tangan sangat perlu diperhatikan agar dapat bereaksi secara tepat dan cepat dalam permainan bulutangkis ini. Pemain bulutangkis yang sudah berpengalaman memiliki kemampuan untuk cepat bereaksi terhadap situasi selama pertandingan dan mampu mengantisipasi pergerakan lawan. ${ }^{5}$

Berdasarkan pemaparan tersebut, diketahui bahwa koordinasi mata tangan dan kekuatan otot genggam dapat mendukung keberhasilan ketepatan pukulan forehand smash, maka dari itu peneliti tertarik untuk melakukan penelitian tentang Hubungan Koordinasi Mata Tangan dan Kekuatan Otot Genggam Dengan Ketepatan Pukulan Forehand Smash Pada Atlet Bulutangkis di Perkumpulan Bulutangkis se-Denpasar.

\section{METODE}

Penelitian ini adalah penelitian observasional yang menggunakan rancangan penelitian desain cross sectional (potong lintang), di mana tiap subjek hanya diobservasi satu kali dan pengukuran variable subjek dilakukan pada saat pemeriksaan. Penelitian ini terdapat tiga buah variable, dua kedudukan sebagai variabel bebas yaitu koordinasi mata tangan dan kekuatan otot genggam sedangkan satu kedudukan untuk variabel terikat yaitu ketepatan pukulan forehand smash.

Pada penelitian ini yang menjadi sampel yaitu atlet bulutangkis putra di PB. Porwaja, di PB. Anugrah, dan di PB. Tunas Remaja yang berusia 15-17 tahun dengan pengambilan sampel secara proportionate cluster random sampling yang telah memenuhi krtiteria inklusi dan eksklusi dan didapatkan atlet di PB. Porwaja sebanyak 30 orang, di PB. Anugrah sebanyak 19 orang dan di PB. Tunas Remaja sebanyak 13 orang sehingga total menjadi 62 sampel.

Kriteria inklusi: Berjenis kelamin laki-laki, berusia 15-17 tahun, daftar hadir latihan dua bulan terakhir 75\% (keaktifan mengikuti latihan, bersedia secara sukarela sebagai subjek penelitian dari awal sampai akhir penelitian dengan menandatangani informed consent bersedia sebagai sampel, keadaan umum sehat, vital sign dalam batas normal. Sedangkan kriteria eksklusi: Memiliki riwayat fraktur atau cedera musculoskeletal pada tangan (ekstremitas atas).

Subjek penelitian dilakukan pengukuran koordinasi mata tangan menggunakan lempar tangkap bola tennis ke dinding sebanyak 20 kali, kekuatan genggaman menggunakan Hand-Grip Dynamometer, dan pengukuran ketepatan pukulan forehand smash dengan melakukan pukulan smash sebanyak 20 kali. Data dianalisis bivariat menggunakan uji Spearman rho, dan analisis multivariat menggunakan regresi berganda.

HASIL

Tabel 1. Karakteristik Sampel

\begin{tabular}{|c|c|c|c|}
\hline Variabel & Frekuensi (n) & Persentase & Rerata \pm SD \\
\hline Umur & & & \\
\hline 15 th & 30 & 48,4 & \\
\hline 16 th & 32 & 51,6 & \\
\hline Koordinasi Mata Tangan & & & \multirow{6}{*}{$11,31 \pm 3,735$} \\
\hline Kurang Sekali & 4 & 6,5 & \\
\hline Kurang & 12 & 19,4 & \\
\hline Sedang & 27 & 43,5 & \\
\hline Baik & 18 & 29,0 & \\
\hline Baik Sekali & 1 & 1,6 & \\
\hline Kekuatan Otot Genggam & & & \multirow{3}{*}{$33,831 \pm 4,2261$} \\
\hline Lemah & 30 & 48,4 & \\
\hline Normal & 32 & 51,6 & \\
\hline Ketepatan Pukulan Forehand Smash & & & \multirow{4}{*}{$16,47 \pm 10,666$} \\
\hline Kurang Sekali & 45 & 72,6 & \\
\hline Kurang & 12 & 19,4 & \\
\hline Cukup & 5 & 8,1 & \\
\hline
\end{tabular}

Berdasarkan Tabel 1. dari 62 atlet menunjukan bahwa sampel terbanyak pada usia 16 tahun yaitu 32 orang atau sebanyak 51,6\%. Rerata koordinasi mata tangan adalah 11,31 \pm 3,735 dan sebagian besar sampel memiliki koordinasi mata tangan dengan kategori sedang sebanyak 27 orang dengan persentase 43,5\%, diikuti dengan koordinasi mata tangan kategori baik sebanyak 18 orang dengan persentase $29,0 \%$ kemudian koordinasi mata tangan dengan kategori kurang sebanyak 12 orang dengan persentase 19,4\% sedangkan kategori kurang sekali sebanyak 4 orang dengan persentase $6,5 \%$ dan koordinasi mata tangan kategori baik sekali sebanyak 1 orang dengan persentase $1,6 \%$. Dilihat dari sebaran distribusi kekuatan otot genggam, sebanyak 62 sampel menunjukkan rerata kekuatan otot genggam adalah $33,831 \pm 4,2261$. Sampel dengan kategori normal sebanyak 32 orang dengan persentase $51,6 \%$ sedangkan dengan kategori lemah sebanyak 30 orang dengan persentase 48,4\%. Menurut data 62 sampel, menunjukkan rerata ketepatan pukulan forehand smash adalah 16,47 $\pm 10,666$. Sebagian besar sampel memiliki ketepatan pukulan forehand smash dengan kategori kurang sekali sebanyak 45 orang dengan persentase $72,6 \%$, di ikuti dengan sampel yang memiliki ketepatan pukulan forehand smash dengan kategori kurang sebanyak 12 orang dengan persentase $19,4 \%$, dan sampel yang memiliki ketepatan pukulan forehand smash dengan kategori cukup sebanyak 5 orang dengan persentase $8,1 \%$.

Tabel 2. Hubungan Koordinasi Mata Tangan Dengan Ketepatan Pukulan Forehand Smash

\begin{tabular}{ccc}
\hline Korelasi Variabel & Reliabilitas (R) & P value \\
\hline Koordinasi Mata Tangan Dengan Ketepatan Pukulan Forehand Smash & 0,456 & 0.000 \\
\hline
\end{tabular}


Berdasarkan Tabel 2. menunjukan bahwa terdapat hubungan yang signifikan antara koordinasi mata tangan dengan ketepatan pukulan forehand smash $(p<0,05)$ dengan nilai koefisien korelasi sebesar 0,456 . Hal ini menunjukan terdapat hubungan yang sedang, signifikan, dan searah antara koordinasi mata tangan dengan ketepatan pukulan forehand smash pada atlet bulutangkis di Denpasar yaitu semakin tinggi koordinasi mata tangan maka semakin tinggi ketepatan pukulan forehand smash.

Tabel 3. Hubungan Kekuatan Otot Genggam Dengan Ketepatan Pukulan Forehand Smash

\begin{tabular}{ccc}
\hline Korelasi Variabel & Reliabilitas (R) & P value \\
\hline Kekuatan Otot Genggam Dengan Ketepatan Pukulan Forehand Smash & 0,503 & 0,000 \\
\hline
\end{tabular}

Berdasarkan Tabel 3. menunjukan bahwa terdapat hubungan yang signifikan antara kekuatan otot genggam dengan ketepatan pukulan forehand smash $(p<0,05)$ dengan nilai koefisien korelasi sebesar 0,503 . Hal ini menunjukan terdapat hubungan yang sedang, signifikan, dan searah antara kekuatan otot genggam dengan ketepatan pukulan forehand smash pada atlet bulutangkis di Denpasar yaitu semakin tinggi kekuatan otot genggam maka semakin tinggi ketepatan pukulan forehand smash.

Tabel 4. Hubungan Koordinasi Mata Tangan Dan Kekuatan Otot Genggam dengan Ketepatan Pukulan Forehand Smash

\begin{tabular}{|c|c|c|c|c|}
\hline Regresi Variabel & $\mathbf{R}$ & F Hitung & F Tabel & $P$ value \\
\hline $\begin{array}{l}\text { Koordinasi mata tangan dan kekuatan otot genggam } \\
\text { dengan ketepatan pukulan forehand smash }\end{array}$ & 0,501 & 9,868 & 3,15 & 0,000 \\
\hline
\end{tabular}

a. Variabel Dependen : Ketepatan Pukulan Forehand Smash

Berdasarkan Tabel 4. menunjukan bahwa terdapat hubungan yang signifikan antara koordinasi mata tangan dan kekuatan otot genggam dengan ketepatan pukulan forehand smash dengan $F$ hitung $>F$ tabel $(9,868>3,15)$ atau $p<$ 0,05 . Korelasi $(R)$ yang secara simultan (bersama-sama) antara variabel koordinasi mata tangan dan kekuatan otot genggam dengan ketepatan pukulan forehand smash diperoleh nilai sebesar 0,501. Koefisien determinasi yang diberikan oleh kedua variabel bebas dengan variabel terikat yaitu sebesar $K D=(R)^{2} \times 100 \%=(0,501)^{2} \times 100 \%=25 \%$ sedangkan sisanya $75 \%$ dipengaruhi oleh variabel lain yang tidak diteliti.

Tabel 5. Hubungan Koordinasi Mata Tangan Dan Kekuatan Otot Genggam

\begin{tabular}{cccccc}
\multicolumn{6}{c}{ dengan Ketepatan Pukulan Forehand Smash } \\
\hline Variabel & B & Std. Error & T Hitung & P value & T Tabel \\
\hline Koordinasi Mata Tangan & 0,269 & 0,093 & 2,007 & 0,049 & \multirow{2}{*}{2,001} \\
Kekuatan Otot Genggam & 0,302 & 0,167 & 2,256 & 0,028 & \\
\hline
\end{tabular}

a. Variabel Dependen : Ketepatan Pukulan Forehand Smash

Berdasarkan Tabel 5. menunjukkan bahwa koordinasi mata tangan dan kekuatan otot genggam secara parsial (sendiri-sendiri) dapat berhubungan secara signfikan terhadap ketepatan pukulan forehand smash. Koordinasi mata tangan berhubungan secara signifikan $(p<0,05)$ atau $T$ hitung $>$ T tabel $(2,007>2,001)$ dan kekuatan otot genggam berhubungan secara signifikan $(p<0,05)$ atau $T$ hitung $>T$ tabel $(2,256>2,001)$. Pada setiap peningkatan nilai dari ketepatan pukulan forehand smash, kekuatan otot genggam memberikan kontribusi lebih besar yaitu 0,302 dibandingkan dengan koordinasi mata tangan yaitu 0,269.

\section{DISKUSI \\ Hubungan Koordinasi Mata Tangan Dengan Ketepatan Pukulan Forehand Smash}

Koordinasi mata tangan tujuan akhirnya adalah menempatkan tangan/jari atau efektor manual pada posisi yang diperlukan untuk pelaksanaan program motorik. Jangkauan neuroanatomi yang paling bertanggungjawab langsung untuk gerakan lengan dan tangan adalah daerah kortikal motorik seperti korteks motorik primer (M1) dan korteks suplementer dan premotor. Korteks motorik primer dimulai pada dinding anterior sulkus sentral dan berlanjut secara rostral untuk membentuk lobulus paracentral anterior. Area kortikal ini yang bertanggungjawab untuk generasi kolektif potensial aksi yang menyampaikan informasi saraf turun ke traktus kortikospinalis untuk menghasilkan gerakan tangan. Korteks premotor (PMC) terletak di bagian anterior korteks motorik primer (M1) dalam posisi lateral dari garis tengah yang berdekatan dengan sulkus precentralis inferior.

PMC adalah wilayah perencanaan untuk gerakan antisipatif, memberikan petunjuk spasial selama gerakan tangan, dan memproses input sensorik yang digunakan untuk membantu gerakan tangan. Korteks motorik suplementer digunakan untuk merencanakan gerakan manual. Area motorik ini memasok sebagian besar neuron yang aksonnya membentuk traktus kortikospinalis, yang berjalan melalui kapsula interna dan pons, decusatio pada tingkat medulla, dan pada akhirnya mengaktifkan motor neuron alfa di sumsum tulang belakang (terutama tingkat servikal dan torakal) baik secara langsung atau melalui interneuron spinal. ${ }^{6}$

Jangkauan kortikal dilengkapi dengan jaringan yang lebih besar dari daerah kortikal dan subkortikal, termasuk korteks posterior parietal (PPC), korteks somatosensori, ganglia basalis, dan cerebellum. PPC adalah wilayah asosiatif yang menerjemahkan informasi visual dan input dari korteks somatosensori menjadi perintah motorik. Korteks anterior intraparietal area (AIP) terlibat langsung dalam gerakan tangan menggenggam dan preshaping tangan. Bagian anterior intraparietal sulkus (IPS) memonitor kompatibilitas jangkauan/pegangan dengan input sensorik yang masuk dan perintah (output) berupa gerakan.Gerakan mata sering terjadi sebelum gerakan tangan. Mata akan mengarahkan pandangan langsung pada target sebelum gerakan tangan. ${ }^{6}$

Hasil ini serupa dengan penelitian yang dilakukan oleh (Hermansyah, et al., 2017) yang meneliti tentang power otot lengan dan koordinasi mata tangan dengan kecepatan dan ketepatan smash dalam cabang olahraga bulutangkis. 
Hasil penelitian tersebut menunjukkan $(r=0,615, p=0,004)$ yang menunjukkan hubungan yang signifikan dan semakin besar koordinasi mata tangan maka semakin besar ketepatan pukulan smash. ${ }^{7}$ Penelitian lainnya yang dilakukan oleh (Yusuf, 2015) mengatakan bahwa koordinasi khusus merefleksikan kemampuan seseorang untuk membentuk berbagai gerakan dalam olahraga dengan cepat, nyaman, sempurna dan tepat. Koordinasi mata tangan berperan untuk membuat gerakan-gerakan menjadi sempurna, sehingga gerakan pukulan smash lebih terarah dalam permainan bulutangkis. Mata memberikan informasi mengai gerak suatu objek dari lingkungan yang berguna dalam perilaku motorik. Shuttlecock yang selalu bergerak dan berubah-ubah menuntut pemain memiliki kemampuan dan ketajaman serta mengkoordinasikan dengan gerakan memukul shuttlecock sehingga gerakan dapat dilakukan dengan efektif dan efisien. ${ }^{8}$

\section{Hubungan Kekuatan Otot Genggam Dengan Ketepatan Pukulan Forehand Smash}

Penelitian yang dilakukan oleh (Mulyono, 2015) tentang hubungan power lengan, kekuatan genggaman, dan kekuatan otot tungkai dengan hasil smash penuh menunjukkan bahwa kekuatan genggaman tangan memiliki hubungan yang positif dan signifikan dengan kemampuan smash atlet bulutangkis yang ditunjukkan oleh thitung $>t_{\text {tabel }}(2,392>$ 2,16). ${ }^{9}$ Kekuatan dikenal untuk meningkatkan keberhasilan dan kinerja olahraga terutama kekuatan genggaman tangan yang digunakan sebagai penentu paling penting. Kekuatan genggaman tangan adalah sifat fisik yang memainkan peran penting dalam memberikan efektivitas dan efisiensi dalam kegiatan olahraga. Genggaman tangan merupakan indikator penting dalam banyak jenis olahraga salah satunya bulutangkis. ${ }^{10}$

Penelitian yang dilakukan oleh (Phomsoupha \& Laffaye, 2017) mengenai Predicting level skill in Badminton dimana dalam penelitian tersebut dilakukan pengukuran kekuatan otot genggam dengan hand dynamometer. Hasil penelitian yaitu terdapat hubungan yang signifikan antara kekuatan otot genggam dengan kecepatan shuttlecock yaitu dengan nilai $r=0,42$ dan nilai $p=0,04$. Kekuatan genggaman diperlukan untuk memeras raket dengan kontraksi isometrik selama melakukan pukulan kuat seperti smash dan clear. Penelitian ini juga menyebutkan pentingnya kekuatan otot genggam yang jarang diteliti dalam permainan bulutangkis. Permainan yang dilakukan selama berhari-hari akan menurunkan kemampuan untuk menggenggam kuat raket dimana semakin tinggi kehilangan kekuatan selama permainan maka semakin tinggi kehilangan kecepatan shuttlecock.11

Kekuatan genggaman tangan diperlukan kestabilan dari pergelangan tangan. Pergelangan tangan yang stabil secara biomekanik dapat mencegah terjadinya gerakan berlebih pada fleksi jari dan kekuatan ekstensor ketika tendon bergerak di atas carpus. Tangan manusia merupakan salah satu sistem biomekanik yang paling kompleks. Segmen tulang disusun oleh lengkungan longitudinal dan transversal. Lengkungan transversal terdiri dari dua yaitu lengkungan proksimal disusun oleh tulang carpal dan lengkungan distal disusun oleh distal metacarpal jari-jari. Lengkung longitudinal disusun oleh 5 tulang tangan. Tulang carpal berkontribusi menstabilkan komponen ke lengkungan longitudinal serta struktur terkait pusat ke fungsi tangan. ${ }^{12}$

\section{Hubungan Koordinasi Mata Tangan Dan Kekuatan Otot Genggam Dengan Ketepatan Pukulan Forehand Smash}

Permainan bulutangkis sangat memerlukan kekuatan pada otot dan persendian untuk meningkatkan kecepatan shuttlecock dan untuk mengurangi cedera. Kontak antara raket dan shuttlecock diperlukan untuk eksekusi pukulan yang optimal, dan ini dipengaruhi oleh kekuatan otot genggam. Koordinasi merupakan kemampuan berulang untuk mengeksekusi gerakan secara lancer dan akurat. Koordinasi mata tangan diperlukan untuk mengontrol shuttlecock, kecepatan untuk bereaksi terhadap lingkungan. Koordinasi mata tangan yang baik akan meningkatkan kemampuan pemain untuk melakukan gerakan yang kompleks, merespon secara efektif terhadap rangsangan eksternal dan membuat gerakan yang cepat serta mengontrol kecepatan lengan dan arah pukulan. Karenanya kekuatan otot genggam dan koordinasi mata tangan memainkan peran penting dalam kinerja fungsional utama dalam aktivitas otot dan transfer gaya dalam olahraga. ${ }^{13}$

Smash adalah jenis pukulan yang biasanya digunakan untuk mematikan lawan dan untuk mendapatkan poin. Untuk melakukan gerakan yang tepat diperlukan gerakan dan faktor mental yang baik. Gerakan smash membutuhkan kekuatan dari otot lengan untuk berayun dibantu oleh gerakan tubuh yang lainnya sehingga menghasilkan pukulan yang kuat dan keras serta memerlukan genggaman yang kuat. ${ }^{14}$ Hasil penelitian yang dilakukan oleh (Yusuf, 2015) tentang Kontribusi Kekuatan Otot Lengan dan Koordinasi Mata Tangan Terhadap Pukulan Smash Pada Bulutangkis Kategori Remaja Putra adalah terdapat kontribusi antara kekuatan otot lengan dan koordinasi mata tangan secara bersamasama terhadap pukulan forehand smash dengan nilai korelasi sebesar 0,907 yang artinya mempunyai hubungan yang sangat kuat, positif, dan signifikan. ${ }^{8}$ Pukulan smash banyak didominasi oleh kekuatan otot lengan, namun kekuatan genggaman tangan juga memiliki pengaruh yang besar dalam pukulan smash ini dikarenakan kekuatan genggaman tangan sangat berperan pada penempatan shuttlecock. ${ }^{4}$ Kemampuan antisipasi gerakan yang baik diperlukan agar dapat menciptakan gerakan efektif. Ketepatan dalam mengantisipasi gerak shuttlecock ditentukan oleh mata dan kemampuan koordinasi gerak. Koordinasi khusus berkaitan dengan keterampilan gerak serta meningkatkan kemampuan atlet dalam berlatih dan bertanding. ${ }^{8}$

\section{SIMPULAN}

Berdasarkan hasil penelitian, maka dapat disimpulkan bahwa koordinasi mata tangan berhubungan dengan ketepatan pukulan forehand smash, kekuatan otot genggam berhubungan dengan ketepatan pukulan forehand smash, koordinasi mata tangan dan kekuatan otot genggam berhubungan dengan ketepatan pukulan forehand smash pada atlet bulutangkis Kota Denpasar. 


\section{DAFTAR PUSTAKA}

1. Wahyuni N, Nugraha MHS, Juhanna IV. Olahraga Dapat Meningkatkan Fungsi Kognitif Melalui Modulasi Epigenetik Ekspresi Gen Brain-Derived Neurotrophic Factor (BDNF). Bali; 2018.

2. Bankozs Z, Nawara H, Ociepa M. Assessment of Simple Reaction Time in Badminton Players. TRENDS in Sport Sciences. 2013;1(20):54-61.

3. Harmawan ST. Uji Validitas Dan Reliabilitas Instrumen Tes Forehand Smash Dari James Poole Untuk Cabang Olahraga Bulutangkis. Universitas Pendidikan Indonesia; 2015.

4. Koley S, Goud S. Correlations of handgrip strength with selected anthropometric variables in Indian junior and senior badminton players. International Journal of Recent Scientific Research. 2016;7(4):10351-10355.

5. Dube SP, Mungal SU, Kulkarni MB. Simple visual reaction time in badminton players: a comparative study. National Journal of Physiology, Pharmacy \& Pharmacology. 2015;5(1):18-20.

6. Rizzo JR, Hosseini M, Wong EA, Mackey WE, Fung JK, Ahdoot E, Rucker JC, Raghavan P, Landy MS, Hudson TE. The intersection between ocular and manual motor control: eye-hand coordination in acquired brain injury. Frontiers in neurology. 2017;8(227):1-17.

7. Hermansyah R, Imanudin I. Hubungan Power Otot Lengan Dan Koordinasi Dengan Kecepatan Dan Ketepatan Smash Dalam Cabang Olahraga Bulutangkis. Jurnal Terapan IImu Keolahragaan. 2017;2(1):44-50.

8. Yusuf MA. Kontribusi Kekuatan Otot Lengan dan Koordinasi Mata Tangan Terhadap Pukulan Smash Pada Bulutangkis Kategori Remaja Putra. Kesehatan Olahraga. 2015;3(1):22-30.

9. Mulyono MT. Hubungan Power Lengan, Kekuatan Genggaman, Dan Kekuatan Otot Tungkai Dengan Hasil Smash Penuh. Semarang; 2015.

10. Wagh PD, Birajdar G, Nagavekar M. Comparison Of Handgrip Muscle Strength In Sportsmen And Sedentary Group. IOSR Journal of Dental and Medical Sciences. 2017;16(7):62-65.

11. Phomsoupha M, Laffaye G. Multiple Repeated-Sprint Ability Test With Four Changes of Direction for Badminton Players (Part 2): Predicting Skill Level With Anthropometry, Strength, Shuttlecock, and Displacement Velocity. The Journal of Strength \& Conditioning Research. 2020;34(1):203-11.

12. Duncan SFM, Saracevic CE, Kakinoki R. Biomechanic of The Hand. Hand Clin. 2013;29:483-492.

13. Pipal BP, Gaur DK, Dahiya J. Correlation between Hand Grip Strength and Hand Eye Coordination with Performance in Adolescent Tennis Players. International Journal of Science and Research. 2017;6(3).

14. Akbari M, Dlis F, Widiastuti W. The Effect At Muscle Power Arm, Hand-Eye Coordination, Flexibility And Self Confidence Upon Badminton Smash Skill. Indonesian Physical Education and Sport. 2017;3(2):84-94. 